Astra-Zeneca, Astro, BMS, Celgene, Celltrion, Chugai, Gilead Glaxo, ILTOO, Janssen, Eli Lilly and Company, Medimmune, MSD, Novartis-Sandoz, Pfizer, Roche, Samsung, Sanofi-Aventis, UCB, G. Burmester Consultant for: Eli Lilly and Company, C. Walls Shareholder of: Eli Lilly and Company, Employee of: Eli Lilly and Company, W.-S. Wu Shareholder of: Eli Lilly and Company, Employee of: Eli Lilly and Company, C. Dickson Shareholder of: Eli Lilly and Company, Employee of: Eli Lilly and Company, R. Liao Shareholder of: Eli Lilly and Company, Employee of: Eli Lilly and Company, M. Genovese Grant/research support from: Eli Lilly and Company, AbbVie, Consultant for: Eli Lilly and Company, AbbVie, DOI: 10.1136/annrheumdis-2018-eular.1935

\section{FRI0078 PROSPECTIVE FOLLOW-UP OF A COHORT OF PATIENTS WITH INTERSTITIAL LUNG DISEASEASSOCIATED WITH RHEUMATOID ARTHRITIS IN TREATMENT WITH DMARD}

N. Mena-Vázquez ${ }^{1}$, C. Gomez-Cano ${ }^{2}$, L. Perez-Albaladejo ${ }^{3}$, S. Manrique-Arija ${ }^{1}$, C. Romero-Barco ${ }^{4}$, C. Aguilar-Hurtado ${ }^{5}$, I. Ureña-Garnica ${ }^{6}$, F. Jiménez-Núñez ${ }^{1}$ M. Ordóñez-Cañizares ${ }^{1}$, C. Fuego ${ }^{1}$, M. Padin-Martin ${ }^{5}$, R. Caliz-Caliz ${ }^{3}$,

A. Fernández-Nebro. . ' UGC de Reumatología, Instituto de Investigación Biomédica de Málaga (IBIMA) Hospital Regional Universitario de Málaga, Universidad de Málaga., Málaga; ${ }^{2}$ Department of Rheumatology, Hospital Virgen de Valme, Sevilla; ${ }^{3}$ Department of Rheumatology Hospital Virgen de las Nieves. Granada; ${ }^{4}$ UGC de Reumatología, Instituto de Investigación Biomédica de Málaga (IBIMA), Hospital Clínico Virgen de la Victoria, Universidad de Málaga; ${ }^{5}$ Department of Radiology Hospital Regional de Málaga; ${ }^{6}$ Department of Rheumatology at the University Regional Hospital of Malaga (HRUM). Institute for Biomedical Research in Malaga (IBIMA). Malaga University, ${ }^{7}$ UGC de Reumatología, Instituto de Investigación Biomédica de Málaga (IBIMA) Hospital Regional Universitario de Málaga, Departamento de Medicina y Dermatología, Universidad de Málaga., Málaga, Spain

Objectives: To describe prospectively the evolution of interstitial lung disease (ILD) in RA treated with modifying antirheumatic drugs (DMARDs) in clinical practice.

Methods : Design: Multicenter prospective observational cohort. Patients: Patients with RA (ACR/EULAR 2010 criteria) and ILD (American Thoracic Society) from different centres of Málaga, Valme Hospital of Sevilla and Virgen Nieves of Granada were included. Protocol: All patients with RA and ILD who visited clinic from 2015 to 2017 were recruited. They were reviewed according to a predetermined protocol for data collection. Resolution Computed Tomography (HRCT), Pulmonary function test (PFT) and echocardiogram were requested for all patients who did not have it in the last year. This visit was marked as v0 (index date). At 12 months (v12) the joint assessment (DAS28), echocardiogram, PTF and HRCT were again evaluated. HRCT's were assessed by the same radiologist. Outcomes: At v12:( ${ }^{1}$ improvement (ie improvement in FVC $\geq 10 \%$ or DLCO $\geq 15 \%$ and no radiological progression), ${ }^{2}$ non-progression (stabilisation or improvement in FVC $\leq 10 \%$ or DLCO $<15 \%$ and no radiological progression), ${ }^{3}$ progression (worsening of FVC $>10 \%$ or DLCO $>15 \%$ and radiological progression), or $^{4}$ death due to ILD. Variables: Description of ILD type and lung function by PTF, HRCT. Presence of PTH by echocardiogram and dyspnoea. Disease activity by DAS28-ESR;Adverse events during the follow-up period. Statistical analysis: Descriptive analysis and Wilcoxon or T test between the v0 and v12. One factor ANOVA between SDMARD, bDMARD and combination therapy groups.

Results: The main characteristics at $\mathrm{V} 0$ of the patients $(n=41)$ are shown in the table 1 . Nine patients $(21.9 \%$ ) received a sDMARDs with a bDMARDs;25 patients $(60.9 \%)$ monotherapy with sDMARD and $7(17.0 \%)$ monotherapy with bDMARDs (table 1). Nine patients (21.9\%) had improvement (2 with MTX, 1 with MTX $+\mathrm{HCQ}$, 2 with RTX, $2 \mathrm{HCQ}+\mathrm{RTX}, 1 \mathrm{MMF}+\mathrm{RTX}$ and 1 with $\mathrm{ABA}) ; 24$ patients $(58.5 \%)$ remained stable ( 6 with MTX, 6 with LFN, 3 with HCQ, 1 AZA, 1 SSZ, 1 MMF, 1 TCZ, 2 ABA, $1 \mathrm{MTX}+\mathrm{ETN}, 1 \mathrm{HCQ}+\mathrm{RTX}, 1 \mathrm{HCQ}+\mathrm{ADA}, 1 \mathrm{RTX}+\mathrm{MMF})$; and 7 $(17.0 \%)$ got worse of ILD (2 with MTX developed lung nodules not known, 2 with LFN, 1 with LFN +IFX, 1 with ETN +MTX and 1 with SSZ). One patient died due to respiratory infection (with RTX). Two patients developed PPH. We did not find significant differences between Vo DAS28 and v12 (2.61 [0.74] vs 2.54 [1.12]; $\mathrm{p}=0.684)$ or in $\mathrm{HAQ}(1.12[0.89]$ vs $1.23[0.73], \mathrm{p}=0.368)$. There were no significant differences in PTF, HRCT or DAS28 between SDMARD, bDMARD and combination therapy groups. During the follow-up period 27 patients had infections, the majority $(53.7 \%)$ respiratory infection.

\begin{tabular}{|c|c|}
\hline VARIABLES & Patients \\
\hline Sex (male), $n(\%)$ & $21(51.2)$ \\
\hline Age (years), mean (DE) & $67.9(7.8)$ \\
\hline Smoker, n (\%) & $8(19,5)$ \\
\hline Ex-smoker, n(\%) & $32(78)$ \\
\hline Body mass index (BMI), mean (SD & $28.7(5.3)$ \\
\hline Disease duration (months), median ( $p 25-p 75$ ) & $138.1(77.7-285.3)$ \\
\hline ILD duration (months), median (p25-p75) & $41.4(10.1-79.2)$ \\
\hline Rheumatoid factor, $\mathrm{n}(\%)$ & $39(95.1)$ \\
\hline Anti-cyclic citrullin ated peptide, $n(\%)$ & $35(85.4)$ \\
\hline Erosions, n (\%) & $27(66)$ \\
\hline DAS28, mean (DE) & $2.8(0.8)$ \\
\hline$H A Q$, mean (DE) & $1.2(0.8)$ \\
\hline \multicolumn{2}{|l|}{ Treatment } \\
\hline sDMARD, $n(\%)$ & $34(82.9)$ \\
\hline Methotrexate, $n(\%)$ & $13(31.7)$ \\
\hline Leflunomide, $n(\%)$ & $9(22.0)$ \\
\hline Sulfasalazine, $n(\%)$ & $2(4.9)$ \\
\hline Hydroxychloroquine, $n$ (\%) & $6(14.6)$ \\
\hline Azathioprine & $1(2.4)$ \\
\hline Micofenolato & $3(7.3)$ \\
\hline MTX+HQC & $2(4.9)$ \\
\hline bDMARDs, n (\%) & $16(39.0)$ \\
\hline Rituximab, $n(\%)$ & $7(17.1)$ \\
\hline Abatacept, $\mathrm{n}(\%)$ & $3(7.3)$ \\
\hline Etanercept, $n(\%)$ & $3(7.3)$ \\
\hline Infliximab, n (\%) & $1(2.4)$ \\
\hline Adalimumab, $\mathbf{n}(\%)$ & $1(2.4)$ \\
\hline Tocilizumab, $n(\%)$ & $1(2.4)$ \\
\hline
\end{tabular}

Conclusions: Most patients with RA and ILD who are receiving treatment with DMARD $(80.5 \%)$ remained stable or improved after at least one year of both synthetic and biological DMARD treatment. More prospective studies are necessary to identify the influence of DMARDs in this evolution.

Disclosure of Interest: None declared

DOI: 10.1136/annrheumdis-2018-eular.4100

\section{FRI0079 ADIPONECTIN LEVEL, INSULIN RESISTANCE, ENDOTHELIAL DYSFUNCTION IN FEMALES WITH RHEUMATOID ARTHRITIS AND COMORBID HYPERTENSION}

O. Sirenko, O. Kuryata, T. Lysunets. State Establishment «Dnipropetrovsk medical academy of Health Ministry of Ukraine», Dnipropetrovsk, Ukraine

Background : Rheumatoid arthritis (RA) associates with accelerated atherosclerosis and high cardiovascular mortality. Cardiovascular risk assessment in RA pts with comorbid hypertension (HT) is do not fully reflected by traditional risk scales, thus additional factors searching is required.

Objectives: We aimed to estimate the adiponectin level, insulin resistance, endothelial function in RA females with comorbid HT and its relationship with subclinical manifestations of atherosclerosis.

Methods: The study included 82 RA females with low disease activity and comorbid HT (mean age of 54.6 [49.7; 62.5] years) and $40 \mathrm{HT}$ females without RA (control group). All pts received stable therapy of RA more than 6 months. Pts with coronary artery disease were excluded. The risk of fatal cardiovascular disease was calculated using mSCORE. RA disese activity was measured using DAS28 scale. Carotid ultrasound detection and endothelial-dependent flow mediated vas odilatation (EDVD) by Celermajer method were performed. The levels of adiponectin, insulin were measured using ELISA kit test, insulin resistance was estimated using HOMA2 index.

Results: Endothelial dysfunction was established in the majority of main group patients - $61(74.4 \%)$, insulin resistance - in 70 (85.4\%), elevated levels of adiponectin - in 35 (42.7\%). Hypertensive females with RA had significantly higher adiponectin, insulin, insulin resistance levels compare to control $(p<0.05)$. Subclinical manifestations of atherosclerosis were established in $64(78.0 \%) H T$ females with RA and 10 (50\%) control group pts. While the median cardiovascular risk level was $4.2[2.7 ; 6.5] \%$ matched by mSCORE. The presence of atherosclerotic plaques in $\mathrm{HT}$ females with $\mathrm{RA}$ was associated with age $(\mathrm{OR}=1.242, \mathrm{p}=0.004$ $95 \% \mathrm{Cl} 1.007-1.78)$, glucocorticosteroid therapy $>3$ months $(\mathrm{OR}=1.56, p=0.001$ $95 \% \mathrm{Cl} 1.22-2.45)$, endothelial dysfunction $(\mathrm{OR}=3.584, \mathrm{p}=0.001,95 \% \mathrm{Cl} 1.71-$ 4.723), insulin resistance ( $O R=1.684, p=0.011,95 \% \mathrm{Cl} 1.22-2.74)$, abnormal adiponectin level $(\mathrm{OR}=1.71, \mathrm{p}=0.028,95 \% \mathrm{Cl} 1.17-2.43)$. AUROC index for prog nostic role of adiponectin and HOMA2 in subclinical atherosclerosis develop were 0.79 (95\% Cl 0.64-0.95; $\mathrm{p}<0.05)$ and 0.76 (95\% Cl 0.61-0.92; $\mathrm{p}<0.05)$ respectively, that indicate a good quality of diagnostic models. 